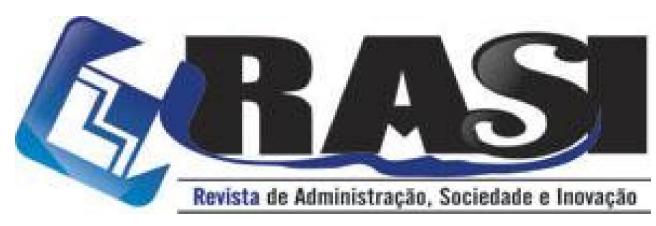

http://www.rasi.vr.uff.br

RASI, Volta Redonda/RJ, v. 6, n. 2, pp. 06-24, mai./ago. 2020

\title{
Limites e Possibilidades do Marco Legal da CT\&I de 2016 para as Instituições Científicas e Tecnológicas do Brasil
}

\author{
Bruno Gomes de Carvalho (UFLA) - bg2490@gmail.com \\ Dany Flávio Tonelli (UFLA) - danytonelli@dae.ufla.br
}

\section{RESUMO}

Este trabalho objetivou analisar os limites e as possibilidades da Lei de Inovação - Lei 13.243 de 2016 - para as instituições científicas e tecnológicas no Brasil. O tema é relevante, pois, dado seu caráter recente, há poucos estudos que demonstram os impactos do novo Marco Legal de Inovação no contexto brasileiro. Na base teórica são abordados o histórico e o contexto atual da ciência, tecnologia e inovação no Brasil. Para realizar o objetivo principal, o método utilizado foi a pesquisa qualitativa com aplicação da técnica de entrevista com especialistas atuantes no âmbito da inovação. Verificou-se, após a análise das entrevistas, que a Lei de Inovação de 2016 é um avanço em relação à lei anterior, visto o potencial que ela proporciona para as ICTs no que tange à aproximação entre o público e o privado, à autonomia referente à política de inovação institucional e aos novos instrumentos jurídicos, dentre outros. Contudo, o principal limite existente na visão dos entrevistados é a falta de uma cultura de inovação (presente nas universidades, governo e empresas) que pode vir a ser um impedimento para a efetividade do Marco Legal de Inovação no país.

PALAVRAS-CHAVES: Inovação. Lei de Inovação. Política de Inovação. Ciência e Tecnologia.

\section{Limits and Possibilities of the New Innovation Law of 2016 for Scientific and Technological Institutions of Brazil}

\begin{abstract}
This work aimed to analyze the limits and possibilities of the Innovation Law - Law 13.243/2016 - for scientific and technological institutions in Brazil. The theme is relevant because, given its recent feature, there are few studies that demonstrate the impacts of the new Legal Innovation framework in the Brazilian context. In the theoretical basis are discussed the historic and the current context of science, technology and innovation in Brazil. To accomplish the main objective, the method used was the qualitative research with the application of the interview technique with specialists working in the context of innovation. It was verified, after the analysis of the interviews, that the Innovation Law of 2016 is an advance in relation to the previous law, given the potential it provides to STIs regarding the approximation between the public and the private, the autonomy related to the innovation policy Institutional and new legal instruments, among others. However, the main limit existing in the interviewees ' view is the lack of a culture of innovation (present in universities, government and companies) that may become an impediment to the effectiveness of the Innovation Law in the country.
\end{abstract}

KEYWORDS: Innovation. Innovation Law. Innovation policy. Science and technology.

\section{SO \\ Fluminense}

R. Desembargador Ellis Hermydio Figueira, 783, Bloco A, sl. 218, Aterrado. 27213-415 - Volta Redonda, RJ - Brasil

www.uff.br

Copyright (C) 2020 RASI. Todos os direitos, até mesmo de tradução, são reservados. É permitido citar parte de artigos sem autorização prévia, desde que seja identificada a fonte. 


\section{Limites e Possibilidades do Marco Legal da CT\&I de 2016 para as Instituições Científicas e Tecnológicas do Brasil}

\section{Introdução}

O Brasil é um país que tem se desenvolvido lentamente, quando o assunto é inovação tecnológica. As leis brasileiras nessa área foram criadas de forma tardia, o que impacta na sua aplicação devido à insegurança jurídica causada pelo ambiente de constantes novidades. Se analisarmos historicamente perceberemos, por exemplo, que a primeira Lei de Inovação foi criada apenas em 02 de dezembro de 2004, enquanto países mais desenvolvidos já se preocupavam há décadas com normatizações similares. Outra legislação de grande importância foi a Lei do Bem, criada em 2005, que visa conceder incentivos fiscais às pessoas jurídicas que realizarem pesquisa e desenvolvimento voltados para a inovação tecnológica, ela reforça os anseios nacionais no tocante à inovação por meio de estímulos que alavancam os investimentos por parte do setor de produção.

A Lei de Inovação de 2004 nasceu de uma necessidade estratégica brasileira de maior interação entre nossa produção científica, que ocorre nas Instituições Científicas e Tecnológicas - ICTs, e o setor produtivo (Matias-Pereira \& Kruglianskas, 2005). Além disso, conforme Matias-Pereira (2013), essa lei buscava superar a ideia de que fazer apenas ciência e/ou pesquisa é suficiente, portanto, era necessário colocá-las em prática, ou seja, inovar. Ressalta-se que, no contexto da inovação, as universidades são responsáveis pela geração de saberes e mão de obra qualificada, a inovação em si ocorre na prática, no ambiente produtivo, por isso devem existir mecanismos legais por parte do Estado que assegurem e desenvolvam o elo entre esses atores (Matias-Pereira \& Kruglianskas, 2005). A Lei do Bem, por sua vez, surgiu da preocupação do Estado em incentivar as empresas a investirem em inovação, visto que, conforme exposto por De Negri e Lemos (2009), um dos obstáculos percebidos pelo empresariado ao tentarem inovar no Brasil é o elevado custo dessa atividade. Com esse arcabouço legal as empresas brasileiras dispunham, segundo De Negri e Lemos (2009, p. 4), de:
a. incentivo fiscal à $\mathrm{P} \& \mathrm{D}$ semelhante à dos principais países do mundo (automática, sem exigências burocráticas);
b. possibilidade de subvenção a projetos considerados importantes para
o desenvolvimento tecnológico;
c. subsídio para a fixação de pesquisadores nas empresas;
d. programas de financiamento à inovação de capital empreendedor;
e. arcabouço legal mais propício para a interação universidade/empresa.

Apesar de todos os benefícios advindos dessas leis, elas possuíam limitações. Em estudo realizado por Matias-Pereira e Kruglianskas (2005), verificou-se que a Lei de Inovação de 2004 possuía imperfeições e ausência de conteúdo, especialmente no que se refere ao estímulo para as micro e pequenas empresas, à interação e regras contratuais entre inventores, ICTs e capital de risco; às regras para as universidades monitorarem os afastamentos de seus docentes para realização de projetos na iniciativa privada, dentre outros. Essas insuficiências traziam insegurança jurídica para os gestores. Argumenta-se, ainda, que existia uma desarticulação entre os instrumentos legais de apoio à inovação e a política de desenvolvimento da produção, dada a rigidez das agências de fomento e pouco uso da capacidade de compra do Estado para estimular a manufatura (De Negri \& Lemos, 2009). 
Por fim, o estudo de Matias-Pereira e Kruglianskas (2005) sobre a Lei de Inovação de 2004, afirma que

"Inúmeras questões complexas não foram tratadas nesta lei, como a criação de mecanismos que permitam sua efetiva conexão com as políticas industrial e tecnológica, bem como a falta de flexibilidade de gestão das instituições de pesquisa, ou seja, a excessiva rigidez que prevalece na gestão de recursos humanos, financeiros e materiais (Matias-Pereira \& Kruglianskas, 2005, p. 15).

As limitações anteriormente citadas foram ganhando notoriedade, o que levou à alteração da Lei de Inovação de 2004, em 11 de janeiro de 2016, por meio da institucionalização de um novo Marco Legal de Inovação - a Lei 13.243, que dispõe sobre estímulos ao desenvolvimento científico, à pesquisa, à capacitação científica e tecnológica e à inovação. Esse novo Marco Legal foi regulamentado por meio do Decreto 9.283 de 07 de fevereiro de 2018. Por ser muito recente, as Instituições Científicas e Tecnológicas ainda estão se adaptando para aplicarem efetivamente o novo Marco Legal.

Com base nesses acontecimentos, o problema de pesquisa aqui proposto é qual o alcance potencial do novo Marco Legal da Inovação para as instituições científicas e tecnológicas? Isto posto, este trabalho tem como objetivo geral identificar qual o alcance potencial do Marco Legal de Inovação de 2016, bem como o seu Decreto de regulamentação, sobre as ICTs do Brasil. Para alcançar o objetivo geral, foram formulados os seguintes objetivos específicos: (i) entender o contexto histórico da inovação no Brasil e (ii) analisar os limites e possibilidades da Lei de Inovação de 2016.

A importância deste estudo se baseia na relevância do tema para o desenvolvimento do país. O novo Marco Legal da Inovação é recente, criado em 2016, isso gera incertezas nas organizações que ele afeta. Dessa forma, é imprescindível estudar suas consequências. Entender como uma política pública relacionada à inovação poderá impactar na prática de gestão das ICTs é crucial.

Para a concretização deste trabalho ele segue organizado da seguinte forma: o referencial teórico contém o histórico da ciência, tecnologia e inovação no contexto brasileiro, trazendo também as discussões recentes acerca da inovação. A metodologia engloba entrevistas com especialistas que atuam profissionalmente em áreas da presente temática. As entrevistas foram transcritas e o seu conteúdo analisado com base na técnica de análise de conteúdo de Bardin (2010). Posteriormente, encontram-se os resultados e discussões e as considerações finais.

\section{Referencial teórico}

O surgimento das primeiras instituições de ensino e pesquisa no Brasil ocorreu entre os anos de 1808 e 1810 (Curso de anatomia e cirurgia, Jardim Botânico do Rio de Janeiro e a Academia Militar). A primeira universidade criada, depois de mais de um século de diferença dessa primeira onda de instituições, foi a USP, em 1934. Esse ponto de partida (e o histórico discutido a seguir) já demonstra que o nosso Sistema Nacional de Inovação se desenvolveu de forma tardia (Suzigan \& Albuquerque, 2008).

O contexto brasileiro que abrange o período colonial até o ano de 1950 foi marcado pela ausência de uma política científica. Após 1930, o enfoque da ciência, e consequentemente do ensino, passou a ser a indústria. Assim, populariza-se no Brasil a criação de universidades e de institutos de pesquisa tecnológica com o objetivo de atender ao 
setor industrial (Morel, 1979). Velho (2011) afirma que a ciência, no período pós-guerra, passaria a ter o papel de motor do progresso. Marco importante desse período foi a criação da Sociedade Brasileira para o Progresso da Ciência - SBPC, em 1948, que buscou defender a relevância da ciência no nível político (Morel, 1979; Vilha et al., 2013; Oliveira, 2016).

O Brasil, até 1950, era basicamente um país agrícola, sem uma industrialização avançada. Essa situação começou a se modificar entre os anos de 1950 e 1980, por meio de uma política voltada para a substituição de importações (Mello; Maculan \& Renault, 2009). Na década de 50, Morel (1979), Vilha et al. (2013) e Oliveira (2016) ressaltam a importância da criação do CNPq - Conselho Nacional de Pesquisas, que ocorreu em 1951. No mesmo ano foi criada a CAPES - Campanha de Aperfeiçoamento de Pessoal de Ensino Superior.

Na década de 60, foi criado, em 1964, o Fundo de Desenvolvimento Tecnológico FUNTEC, administrado pelo Banco Nacional de Desenvolvimento Econômico - BNDE (Suzigan \& Albuquerque, 2008). Precisamente em 1967, Vilha et al. (2013) destacam o surgimento da FINEP - Financiadora de Estudos e Projetos e do FNDCT - Fundo Nacional de Desenvolvimento Científico e Tecnológico. Essa política de incentivo pretendia seguir um modelo de desenvolvimento econômico em que "o sistema científico e a formação de recursos humanos qualificados são vistos como elementos de importância estratégica" (MOREL, 1979, p. 52).

Na década de 70 foi criado o PBDCT - Planos Básicos de Desenvolvimento Científico e Tecnológico, sendo mais um esforço governamental para o desenvolvimento da ciência e tecnologia (Vilha et al., 2013). Nessa década, havia uma tendência, pelo menos em grande parte dos países, de que "não é mais a ciência que empurra a tecnologia (science push), mas o mercado, as necessidades dos usuários que puxam o desenvolvimento científico (demand pull) (Velho, 2011, p. 140). O modelo linear de inovação orientou substancialmente as políticas praticadas nesse período.

$\mathrm{Na}$ década de 80 , a ciência e tecnologia passam por uma importante transformação relacionada com o surgimento das tecnologias da informação. Já o marco institucional, no Brasil, foi a criação do Ministério da Ciência e Tecnologia, em 1985, que assume a responsabilidade política e de planejamento da C\&T (Vilha et al., 2013; Oliveira, 2016). Apesar de sua criação nessa década, foi apenas em 1992 que o Ministério de Ciência e Tecnologia "ganhou estabilidade como órgão central do setor de CT\&I" (Oliveira, p. 143, 2016). Aumentava a percepção de que o modelo linear de ciência e de tecnologia não era capaz de proporcionar o desenvolvimento tecnológico esperado, mas na prática as políticas continuaram sendo orientadas por ele.

No início da década de 90 o contexto da inovação no Brasil foi marcado por diversos cortes orçamentários na ciência (Vilha et al., 2013). Entretanto, no final dos anos 90 surgem os Fundos Setoriais, que possibilitaram novos recursos, mais estáveis, para C\&T apesar do início orçamentário conturbado dessa década (Vilha et al., 2013; Cavalcante, 2013). Corroborando com esses autores, Arbix (2010) afirma que os Fundos Setoriais foram possíveis graças à pressão sobre o governo e graças à atuação do Ministério da Ciência e Tecnologia. Apesar dessa nova possibilidade de financiamento os recursos "continuaram orientados primordialmente para as universidades públicas e os institutos de pesquisa" (Arbix, 2010, p. 22).

Nos anos 2000 existiram importantes ações voltadas para as políticas industriais se destacando entre elas a Política Industrial, Tecnológica e de Comércio Exterior - PITCE (Arbix, 2010). A partir desse momento o Brasil passa a se preocupar com o amparo jurídico relacionado à inovação promulgando duas leis muito importantes: a Lei de Inovação (Lei $\mathrm{n}^{\circ}$ 
10.973/2004) e a Lei do Bem (Lei $\left.{ }^{0} 11.196 / 2005\right)$. A primeira possibilitou mecanismos que visavam melhorar a relação entre a produção científica das universidades e centros de pesquisa com as empresas e a indústria, regulamentando, por exemplo, procedimentos que propiciaram aos pesquisadores das universidades e centros de pesquisa a oportunidade de desenvolver projetos junto a empresas. Já a Lei do Bem propiciou maior regulamentação aos incentivos fiscais para a inovação por meio de subsídios e financiamento (Cavalcante, 2013; Arbix, 2010; Arbix, 2016; Vilha et al., 2013).

A Lei de Inovação de 2004 traz em seu texto a obrigatoriedade às ICTs de criarem os chamados Núcleos de Inovação Tecnológica, responsáveis pela gestão da política institucional de inovação. É possível inferir o papel ímpar dos Núcleos de Inovação Tecnológica para as ICTs, principalmente no que tange ao relacionamento dessas com as empresas. A inovação de fato acontece quando o conhecimento gerado é posto em prática, e os NITs são uma das pontes para que isso ocorra. Contudo, essa relação depende das normas jurídicas existentes. Marinho e Corrêa $(2016$, p.51) afirmam que:

O relacionamento das ICT com as empresas deve ser muito bem estruturado, uma vez que cada ente tem seus objetivos específicos, que acabam coincidindo apenas no interesse de ambos pelo desenvolvimento tecnológico, mesmo que cada um continue com seus interesses particulares sobre esse desenvolvimento.

Em 2007, pesquisas do Ipea apontaram que a competitividade do Brasil dependia fortemente das tecnologias das empresas e dos incentivos à inovação por parte do Estado. (Nazareno, 2016). O Plano Nacional de Ciência, Tecnologia e Inovação, planejado para ser incorporado no período de 2007 a 2010, elevou os investimentos em CT\&I de 0,9\% para $1,4 \%$. Além disso, dentre as prioridades estavam diversas ações voltadas à inovação de fato (Arbix, 2010).

Apesar de todo o esforço histórico brasileiro até aqui apresentado, voltado para o desenvolvimento do Sistema Nacional de Inovação e, consequentemente, de uma estrutura mínima de ciência e tecnologia, ainda existia uma falta de capacidade inovativa por parte da indústria, alta dependência de tecnologias externas e carência de articulação entre nossa estrutura produtiva e nossa estrutura de pesquisa (Albuquerque, 1996; Suzigan \& Albuquerque, 2008; Mello; Maculan \& Renault, 2009).

Os marcos que propiciaram a concretização das políticas de inovação no Brasil estão sintetizados no Quadro 1.

Quadro 1. Marcos históricos da Ciência, Tecnologia e Inovação das últimas décadas.

\begin{tabular}{|c|l|}
\hline Marcos Históricos & \multicolumn{1}{c|}{ Importância } \\
\hline Decreto-Lei 7.903 (1945) & Regulava os direitos e obrigações concernentes à propriedade industrial. \\
\hline SBPC (1948) & $\begin{array}{l}\text { Buscou defender a relevância da ciência no nível político (MOREL, 1979; Vilha } \\
\text { et al., 2013; Oliveira, 2016). Entretanto, a ciência brasileira ainda engatinhava, } \\
\text { apenas. }\end{array}$ \\
\hline CNPQ (1951) & $\begin{array}{l}\text { O CNPQ foi um dos primeiros marcos institucionais no Brasil. Já a CAPES } \\
\text { promoveu melhorias ao nível superior de ensino. Prova da importância de } \\
\text { ambos é a presente atuação até os dias atuais na promoção da ciência, } \\
\text { tecnologia e inovação. }\end{array}$ \\
\hline CAPES (1951) & $\begin{array}{l}\text { Ambas as iniciativas buscaram proporcionar ao Brasil certa independência de } \\
\text { fontes externas de tecnologia por meio do financiamento próprio em projetos } \\
\text { científicos e tecnológicos nacionais (Vilha et al., 2013). }\end{array}$ \\
\hline FNDCT (1967) &
\end{tabular}




\begin{tabular}{|c|c|}
\hline \multicolumn{2}{|c|}{ Quadro 1. Marcos históricos da Ciência, Tecnologia e Inovação das últimas décadas. (Continuação) } \\
\hline Marcos Históricos & \\
\hline Decreto-Lei n $^{\circ} 254$ (1967) & Código da Propriedade Industrial. \\
\hline PBDCT & $\begin{array}{l}\text { Mais um esforço governamental para o desenvolvimento da ciência e tecnologia } \\
\text { (Vilha et al., 2013). Esses planos ainda não objetivaram a inovação } \\
\text { concretamente. }\end{array}$ \\
\hline $\begin{array}{l}\text { Ministério da Ciência e } \\
\text { Tecnologia (1985) }\end{array}$ & Assume a responsabilidade política e de planejamento da ciência e tecnologia. \\
\hline Fundos Setoriais (1999) & $\begin{array}{l}\text { Possibilitaram novos recursos, mais estáveis, para C\&T apesar do início } \\
\text { orçamentário conturbado dessa década (Vilha et al., 2013; Cavalcante, 2013). }\end{array}$ \\
\hline PITCE (2004) & $\begin{array}{l}\text { Importante ação voltada para as políticas industriais. Ao contrário da década } \\
\text { anterior, foi uma das novas iniciativas que propiciaram destacar a importância } \\
\text { da inovação. }\end{array}$ \\
\hline $\begin{array}{l}\text { Lei } \mathrm{n}^{\circ} 9.279 \text {, de } 14 \text { de } \\
\text { maio de } 1996\end{array}$ & Regula direitos e obrigações relativos à propriedade industrial. \\
\hline $\begin{array}{c}\text { Lei } \mathrm{n}^{\mathrm{o}} 10.973, \mathrm{de} \\
02 / 12 / 2004\end{array}$ & $\begin{array}{l}\text { Dispõe sobre incentivos à inovação e à pesquisa científica e tecnológica no } \\
\text { ambiente produtivo. }\end{array}$ \\
\hline $\begin{array}{l}\text { Decreto } \mathrm{n}^{0} 5.563 \text {, de } \\
11 / 10 / 2005\end{array}$ & $\begin{array}{l}\text { Regulamenta a Lei } \mathrm{n}^{\circ} 10.973 / 2004 \text {, que dispõe sobre incentivos à inovação e à } \\
\text { pesquisa científica e tecnológica no ambiente produtivo. }\end{array}$ \\
\hline $\begin{array}{l}\text { Decreto } \mathrm{n}^{\circ} 5.798, \text { de } \\
07 / 06 / 2006 \text { (Lei do Bem) }\end{array}$ & $\begin{array}{l}\text { Regulamenta os incentivos fiscais às atividades de pesquisa tecnológica e } \\
\text { desenvolvimento de inovação tecnológica, de que tratam os artigos. } 17 \text { a } 26 \text { da } \\
\text { Lei } n^{\circ} 11.196 \text {, de } 21 / 11 / 2005 \text {. }\end{array}$ \\
\hline $\begin{array}{l}\text { Lei }^{\circ} 13.243 \text {, de } 11 \text { de } \\
\text { janeiro de } 2016\end{array}$ & $\begin{array}{l}\text { Dispõe sobre estímulos ao desenvolvimento científico, à pesquisa, à capacitação } \\
\text { científica e tecnológica e à inovação e altera as legislações relacionadas. }\end{array}$ \\
\hline $\begin{array}{l}\text { Decreto } \mathrm{n}^{\circ} 9.283 \text {, de } 7 \text { de } \\
\quad \text { fevereiro de } 2018\end{array}$ & $\begin{array}{l}\text { Regulamenta a Lei } \mathrm{n}^{\circ} 10.973 / 2004 \text {, a Lei } \mathrm{n}^{\circ} 13.243 \text {, de } 11 \text { de janeiro de } 2016 \text {, o } \\
\text { art. } 24, \S 3^{\circ} \text {, e o art. } 32, \S 7^{\circ} \text {, da Lei } \mathrm{n}^{\circ} 8.666 \text {, de } 21 \text { de junho de } 1993 \text {, o art. } 1^{\circ} \\
\text { da Lei } \mathrm{n}^{\circ} 8.010 \text {, de } 29 \text { de março de } 1990 \text {, e o art. } 2^{\circ} \text {, caput, inciso I, alínea "g", } \\
\text { da Lei } \mathrm{n}^{\circ} 8.032 \text {, de } 12 \text { de abril de } 1990 \text {, e altera o Decreto } \mathrm{n}^{\circ} 6.759 / 2009 \text {, para } \\
\text { estabelecer medidas de incentivo à inovação e à pesquisa científica e } \\
\text { tecnológica no ambiente produtivo, com vistas à capacitação tecnológica, ao } \\
\text { alcance da autonomia tecnológica e ao desenvolvimento do sistema produtivo } \\
\text { nacional e regional. }\end{array}$ \\
\hline
\end{tabular}

Fonte: Elaboração dos autores.

Depreende-se que a primeira lei dedicada integralmente à inovação no Brasil foi criada apenas em 2004. Ela buscava de fato trazer avanços na relação entre ICTs e o ambiente produtivo nas atividades voltadas à inovação, porém, com o passar dos anos, verificou-se a falta de clareza em muitos pontos o que trouxe insegurança jurídica (Rauen, 2016). Era necessário rever a lei de 2004 para que ela permitisse uma efetiva relação entre ICTs e o setor privado.

Nesse contexto surge a Lei 13.243, de 11 de janeiro de 2016, conhecida como a "nova" Lei de Inovação. Esse novo Marco "dispõe sobre estímulos ao desenvolvimento científico, à pesquisa, à capacitação científica e tecnológica e à inovação" (BRASIL, 2016). Houve diversas alterações em leis anteriores, como a Lei $n^{\circ} 10.973$ (antigo Marco Legal da Inovação), possibilitando maior flexibilidade jurídica aos pesquisadores e às instituições de ciência e tecnologia. A Lei de Inovação de 2016 se baseia, assim, em três grandes eixos: "i) a integração de empresas privadas ao sistema público de pesquisa; ii) a simplificação de processos administrativos, de pessoal e financeiro e iii) a descentralização do fomento ao desenvolvimento de setores de CTI nos Estados e Municípios" (Nazareno, 2016, p. 07).

A Lei de Inovação de 2016 procura: expandir o conceito de ICT, incluindo as instituições de direito privado sem fim lucrativo; flexibilizar a contrapartida do uso das instalações das ICTs - ela pode ser financeira e não financeira; permitir que os recursos 
financeiros sejam diretamente repassados às ICTs pelas contratantes por meio de fundações de apoio (ao invés de guia de recolhimento da união, como era feito anteriormente); permitir que os Núcleos de Inovação Tecnológica tenham a oportunidade de possuir personalidade jurídica própria, podendo, inclusive, atuarem como fundação de apoio às ICTs, dando maior flexibilidade na gestão de seus recursos tanto financeiros quanto humanos (Rauen, 2016). Percebe-se que essas mudanças são uma tentativa de oferecer maior segurança às ICTs visto que antes existiam impedimentos jurídicos que se tornavam obstáculos na atuação delas.

Importante destacar as mudanças proporcionadas pela Lei $\mathrm{n}^{\circ} 13.243 / 2016$ no tocante às fundações de apoio. $O$ acréscimo do parágrafo $7^{\circ}$ no artigo $1^{\circ}$ da Lei 8.985/1994 permite que os recursos e direitos advindos dos convênios, contratos e atividades previstas nos artigos $3^{\circ}$ a $9^{\circ}, 11$ e 13 da Lei 10.973/2004 sejam celebrados pelas fundações. Segundo Rauen (2016), esse é um grande avanço visto que os recursos poderão permanecer nas ICTs, o que implica maior estímulo à inovação.

Apesar do novo Marco Legal trazer muitas modificações positivas em leis anteriores, houve muitos vetos governamentais durante sua elaboração. A lei foi sancionada com 11 vetos. Dentre eles destacam-se

Basicamente, o MF entendeu que a isenção tributária e previdenciária das bolsas, assim como a isenção de impostos relativos a importações simplificadas resultariam em perda de receita e em desequilíbrio previdenciário, ferindo, dentre outras, a Lei de Responsabilidade Fiscal (LRF). Já o MPOG apontou a impossibilidade de cobrança de taxa de administração em convênios e a insegurança jurídica que poderia ser causada pela ampliação da autonomia dada às ICTs mediante a adoção de contrato de gestão. Ademais, ambos os Ministérios opinaram em desfavor da dispensa de licitação ampliada, devido à excessiva flexibilidade permitida (Nazareno, 2016, p. 13).

Corroborando com a análise de Nazareno (2016), Rauen (2016) afirma que há dois vetos muito delicados. O primeiro é em relação à não concessão de bolsas de estímulo à inovação para discentes de ICTs privadas. O segundo está relacionado às despesas operacionais e administrativas na execução de projetos entre ICT-empresa, veto este que remete à alteração do artigo 10 da antiga lei que visava

[...] substituir os termos "acordos e contratos" por "instrumentos" de maneira geral (abarcando a modalidade "convênios", já prevista no regulamento) e inserir "empresas" e "pesquisadores" entre os possíveis participantes das parcerias firmadas, o que confere mais flexibilidade e expande as possibilidades de arranjos possíveis no sistema, ao abranger, por exemplo, as empresas da administração pública. Além disso, propôs incluir no caput da nova redação da lei a possibilidade de "ser aplicada taxa de administração, nos termos do regulamento" (Raeun, 2016, p. 30).

Raeun (2016) destaca que ainda há certa insegurança jurídica especialmente no recebimento de bolsas pelos pesquisadores na prestação de serviços; nas formas de acesso das empresas às ICTs; como as ICTs irão garantir a igualdade de condições às empresas interessadas no uso de suas instalações; e à falta de cobertura das despesas operacionais e administrativas dos projetos de inovação. Nazareno (2016) afirma que o novo Marco Legal da Inovação pode gerar dificuldades aos órgãos fiscalizadores no que tange aos mecanismos de 
controle; além disso, esse autor ressalta que os recursos financeiros públicos tenderiam a ser mais destinados ao setor privado, o que enfraqueceria as instituições públicas de ensino bem como as fundações estatais.

Uma crítica comum entre Nazareno (2016) e Raeun (2016) é que ainda há gargalos no que tange à troca de recursos financeiros entre o setor público e o privado porque o primeiro setor, tradicionalmente, transfere recursos para o segundo setor, o contrário já não ocorre usualmente. O setor público deveria, portanto, ser menos ofertista e mais demandante junto às empresas nos aspectos ligados à inovação. Em suma, "para fomentar a inovação, é necessário conceber, estruturar e articular políticas públicas e arranjos institucionais capazes de coordenar atores-chave como o Estado, as empresas e empresários e as universidades." (Bucci \& Coutinho, 2017, p. 327). Com base nas críticas anteriormente expostas, é possível criarmos um diagrama analítico no Quadro 2.

Quadro 2. Diagrama analítico da Lei de inovação de 2016.

\begin{tabular}{|l|l|}
\hline \multicolumn{2}{|c|}{ Avanços } \\
\hline \multicolumn{1}{|c|}{ Diagrama Analítico - Lei 13.243/2016 } \\
\hline $\begin{array}{l}\text { Maior autonomia financeira às ICTs por meio } \\
\text { das Fundações de Apoio. }\end{array}$ & Insegurança Jurídica. \\
\hline Maior importância aos NITs (papel estratégico). & Como será o acesso das empresas às ICTs. \\
\hline $\begin{array}{l}\text { Os NITs poderão atuar como fundações de } \\
\text { apoio às ICTs. }\end{array}$ & $\begin{array}{l}\text { Como será garantida a igualdade de condições às empresas } \\
\text { interessadas em acessar as instalações das ICTs. }\end{array}$ \\
\hline $\begin{array}{l}\text { Maior facilidade no compartilhamento de de } \\
\text { laboratórios das ICTs. }\end{array}$ & $\begin{array}{l}\text { Os órgãos fiscalizadores terão dificuldade nos mecanismos } \\
\text { de controle na relação empresa e ICT. }\end{array}$ \\
\hline $\begin{array}{l}\text { Possibilidade de o professor dedicar oito horas } \\
\text { semanais a atividades relacionadas à inovação. }\end{array}$ & $\begin{array}{l}\text { Não concessão de bolsa de estímulo à inovação para } \\
\text { alunos de ICT privada. }\end{array}$ \\
\hline
\end{tabular}

Fonte: Adaptado de Rauen (2016).

Após a promulgação da Lei 13.243/2016, a sua regulamentação ocorreu em fevereiro de 2018, por meio do Decreto $\mathrm{N}^{\mathrm{0}} 9.283$, que estabelece "medidas de incentivo à inovação e à pesquisa científica e tecnológica no ambiente produtivo, com vistas à capacitação tecnológica, ao alcance da autonomia tecnológica e ao desenvolvimento do sistema produtivo nacional e regional" (BRASIL, 2018). Ele conta com um total de 84 artigos. Esse número visa dar maior detalhamento jurídico, diminuindo possíveis dúvidas legais.

Dentre os principais pontos trazidos pelo decreto podemos destacar o artigo $4^{\circ}$ que permite às ICTs a participação minoritária do capital social de empresas com objetivo de desenvolver produtos ou processos relacionados à ciência, tecnologia e inovação. $\mathrm{O}$ artigo $6^{\circ}$ prevê a possibilidade da cessão de imóveis (por parte da administração pública direta, agências de fomento e ICTs) para a instalação e consolidação de ambientes de inovação. $\mathrm{O}$ parágrafo $1^{\mathrm{o}}$ do artigo 11 permite à ICT pública celebrar contrato de transferência de tecnologia e de licenciamento com empresas que possuem em seu quadro societário pesquisador público da mesma ICT.

O decreto estabelece, ainda, instrumentos jurídicos de parcerias como o termo de outorga, no artigo 34; acordo de parceria para pesquisa, desenvolvimento e inovação, no artigo 35; e o convênio para pesquisa, desenvolvimento e inovação, no artigo 38. Por fim, vale destacar que há previsão para a prestação de contas por meio de um procedimento simplificado, previsto entre os artigos 47 e 60.

\section{Procedimento Metodológico}


O tipo de pesquisa adotada neste trabalho foi a qualitativa, de caráter exploratório. As técnicas de coleta de dados envolvem aplicação de entrevistas em profundidade, análise documental e reunião de vídeos e material especializado. Os entrevistados foram selecionados com base nos seguintes critérios: (i) notório saber acadêmico e/ou profissional na área de implementação e/ou elaboração de políticas de inovação e (ii) acessibilidade e disponibilidade para a realização de entrevista. Preferencialmente, a amostra de selecionados deveria ser representativa de diversos setores de natureza pública e privada. As pessoas que atenderam aos critérios e concordaram em responder à entrevista trabalham em áreas e organizações distintas, contudo, todos possuem experiências profissionais em políticas de inovação. Além disso, são responsáveis, direta ou indiretamente, pela elaboração e/ou implementação de atividades essencialmente relacionadas à Lei 13.243/2016 e dispõem de uma gama de informações singulares alusivas à inovação, oriundas dos contextos em que atuam, o que os caracterizam como especialistas (Weller \& Zardo, 2013). A multiplicidade de perfis, porém, não foi totalmente satisfatória, pois não contemplou representantes do ramo empresarial/industrial. A dificuldade se deu por não ser possível identificar um especialista de políticas de inovação representante dessa esfera a tempo ${ }^{1}$. Embora isso possa representar uma limitação na formação da amostra, ela foi amenizada uma vez que parte dos participantes (entrevistado 3) é representante de uma grande universidade privada que possui seu próprio parque tecnológico.

O quadro a seguir contém as características dos entrevistados,

Quadro 3. Características dos entrevistados.

\begin{tabular}{|c|l|}
\hline Identificação & \multicolumn{1}{|c|}{ Área de Formação e Atuação em Inovação } \\
\hline Entrevistado 1 & $\begin{array}{l}\text { Formado em Direito, possui mestrado em Direito e Inovação e atua como Professor } \\
\text { de Direito e Coordenador de um Núcleo de Inovação Tecnológica de uma } \\
\text { Universidade Federal. Tem ampla experiência na elaboração de instrumentos de } \\
\text { parceria, termos de cooperação e contratos com o setor privado. }\end{array}$ \\
\hline Entrevistado 2 & $\begin{array}{l}\text { Formado em física com pós-doutorado na mesma área. Atua como professor adjunto } \\
\text { em uma Universidade Estadual e também é coordenador na área de transferência de } \\
\text { tecnologia no Núcleo de Inovação Tecnológica da mesma universidade. É presidente } \\
\text { interino de um Parque Tecnológico e Diretor de um fórum relacionado à inovação. } \\
\text { Participou como membro do Grupo de Trabalho que elaborou a minuta da Lei } \\
\text { 13.243/2016. }\end{array}$ \\
\hline Entrevistado 3 & $\begin{array}{l}\text { Graduado em Sistemas de Informação com pós-doutorado em gestão de ambientes de } \\
\text { inovação. É professor em uma universidade particular há trinta e quatro anos e atua } \\
\text { como superintendente de inovação e desenvolvimento da mesma universidade, sendo } \\
\text { também superintendente responsável pelo parque tecnológico privado que abriga } \\
\text { mais de 150 organizações, as quais empregam mais de 6500 pessoas. }\end{array}$ \\
\hline Entrevistado 4 & $\begin{array}{l}\text { É formado na área de relações internacionais e é diplomata de carreira desde 2007. } \\
\text { Atuou como cônsul adjunto em São Francisco, na Califórnia (Vale do Silício) durante } \\
\text { quatro anos (2013 a 2016) nas áreas de promoção comercial, atração de } \\
\text { investimentos, cooperação científica, tecnológica e educacional. Tem ampla } \\
\text { experiência na cooperação internacional e na atração de negócios. }\end{array}$ \\
\hline
\end{tabular}

Fonte: Elaboração dos autores.

\footnotetext{
${ }^{1}$ No curso de seleção de entrevistados, o SEBRAE foi contatado a fim de auxiliar na identificação de um profissional que pudesse contribuir apresentando a visão da indústria, uma vez que na unidade regional consultada não havia pessoa apta a responder às questões. Não foi possível identificar essa pessoa.
} 
Todas as entrevistas foram gravadas em áudio e, posteriormente, transcritas integralmente. Elas aconteceram no primeiro semestre de 2018 e possuem duração média de 30 minutos. Uma entrevista foi realizada pessoalmente e as outras foram via videoconferência (online) utilizando tanto o Whatsapp quanto o Skype. Foi utilizado um roteiro semiestruturado com perguntas envolvendo os limites e possibilidades do novo Marco Legal da Inovação baseadas no conteúdo do referencial teórico e na análise documental.

Além das entrevistas na íntegra, também foram coletados dados secundários provenientes de entrevistas em vídeos do Youtube, cujos trechos foram devidamente transcritos. Os vídeos analisados se tratavam de um evento em que especialistas se reuniram para debater sobre o Marco Legal de Inovação de 2016. O evento foi nomeado de "Série Impacto Marco Legal da CT\&I". Dentre os membros presentes haviam representantes do SEBRAE, de startups, cientistas, empresários, diretores de fundação, etc.

Além dessas fontes, foi realizada análise documental de forma a possibilitar maior gama de informações relevantes. Dentre os documentos analisados estão o Marco Legal da Inovação na íntegra, o seu Decreto de Regulamentação de 2018, um E-book elaborado pela Fundação de Desenvolvimento da Pesquisa - Fundep que discute o impacto do Marco Legal da Inovação e, por fim, notícias acerca do tema. Os dados da pesquisa que constituíram o corpus de análise foram tratados com base na análise de conteúdo de Bardin (2010). A primeira etapa do método é a pré-análise. A segunda etapa é a exploração do material que "consiste na construção das operações de codificação, considerando-se os recortes dos textos em unidades de registros, a definição de regras de contagem e a classificação e agregação das informações em categorias simbólicas ou temáticas" (Silva, 2015, p. 4). Nesta etapa foram definidas as categorias de análise do conteúdo, foi utilizado o processo por acervo, ou seja, as categorias foram definidas posteriormente, de forma progressiva. Este processo também é conhecido como grade aberta, em que as categorias são definidas durante a leitura do corpus de análise, permitindo o remanejamento de elementos entre as categorias e a inclusão, exclusão e alteração das próprias. Importante destacar, ainda, que as categorias de análise foram definidas antes da realização das entrevistas. As categorias deste trabalho podem ser encontradas adiante, no Quadro 4. A terceira e última etapa é o tratamento dos resultados obtidos e interpretação de todo material utilizado na pesquisa (entrevistas, documentos e observação) levando como base comparativa o referencial teórico (Silva, 2015).

\section{Resultados e análises}

Para alcançar os resultados deste trabalho o corpus de análise foi baseado nos limites e possibilidades da Lei 13.243/2016. Para isso foram utilizadas cinco categorias, elencadas no quadro abaixo, de modo a nortear o estudo.

Quadro 4. Categorias de Análise.

\begin{tabular}{|c|}
\hline Categorias De Análise \\
\hline Política institucional \\
\hline Relação entre público e privado \\
\hline Empreendedorismo \\
\hline Papel dos órgãos de controle \\
\hline Fontes de financiamento \\
\hline
\end{tabular}

Fonte: Elaboração dos autores.

Cada categoria engloba os limites e possibilidades que auxiliaram no entendimento global dos impactos da Lei de Inovação de 2016. 


\subsection{Política Institucional}

Foi possível perceber que o Marco Legal de Inovação de 2016 busca respeitar a individualidade das ICTs. O entrevistado 1 destaca que a Lei 13.243/2016, se comparada com a anterior, traz maior segurança jurídica o que influenciará na própria elaboração da política de inovação institucional visto que haverá menos riscos ligados à interpretação jurídica. $\mathrm{O}$ entrevistado 2 afirma ser um avanço cada ICT ter sua regra, dada a maior compatibilidade com suas capacidades internas e regionalidades próprias.

As afirmações dos entrevistados vão ao encontro do chamado "Dissenso Confuso" que afirma que "as políticas de inovação adotadas no país carecem de uma estrutura institucional adequada a sua implementação" (Cavalcante, 2013, p. 23). Nessa abordagem há duas interpretações possíveis ao relacionarmos com as falas dos entrevistados. A primeira é que cabe a cada ICT se preparar institucionalmente para usufruir e aplicar as possibilidades da Lei 13.243/2016, de acordo com suas especificidades, alcançando uma estrutura que absorverá a inovação. A segunda diz respeito ao fato que as ICTs podem não alcançar uma estrutura/política institucional adequada gerando como consequência a falha da implementação da política pública de inovação.

Quadro 5. Possibilidades - Política Institucional.

\begin{tabular}{|c|l|}
\hline \multicolumn{2}{|c|}{ Possibilidades - Política Institucional } \\
\hline ENTREVISTADO 4 & $\begin{array}{l}\text { (...) o Marco Legal, ele tem esse condão, de cima para baixo: conseguir } \\
\text { mudar uma cultura de empreendedorismo, de inovação, que não existia } \\
\text { na academia brasileira. }\end{array}$ \\
$\begin{array}{l}\text { (...) aquele que é refratário a esse tipo de cultura vai acabar tendo que } \\
\text { assimilar porque não tem outra saída." }\end{array}$ \\
\hline
\end{tabular}
Fonte: Elaboração dos autores.

Outro fator de destaque relaciona-se com a afirmação de que o Marco Legal da Inovação de 2016 poderá contribuir para uma mudança no cenário da cultura da inovação presente no país. Atualmente, esse é um grande fator limitante da inovação no Brasil. Quanto aos limites existentes na categoria da política institucional a maior parte dos especialistas destacaram a problemática da cultura da inovação. Não basta ter apenas um arcabouço jurídico, é necessário um novo comportamento diante da inovação por parte das ICTs, empresas e pessoas.

"A cultura organizacional é vista como um dos determinantes da inovação" (Machado et al., 2013, p. 165). A cultura organizacional pode ser vista como um conjunto de valores, crenças, histórias, hábitos, dentre outros, assimilados e aprovados pelos atuais e futuros membros de um grupo, sendo um modo de pensar, agir e até mesmo enfrentar problemas (Maximiano, 2009). Os trechos das falas do Quadro 6 reforçam a ideia.

Quadro 6. Limites - Política Institucional.

\begin{tabular}{|c|c|}
\hline \multicolumn{2}{|r|}{ Limites - Política Institucional } \\
\hline ENTREVISTADO 1 & $\begin{array}{l}{[\ldots] \text { o problema do jurista e da tradição cultural e jurídica brasileira é, }} \\
\text { primeiro, uma extrema desconfiança do administrador público }[\ldots]\end{array}$ \\
\hline ENTREVISTADO 4 & $\begin{array}{l}\text { [...] o mais importante, na minha opinião, é que haja uma mudança cultural } \\
\text { no Brasil, no sentido de que na academia se olhe para a inovação como algo, } \\
\text { como uma grande oportunidade. } \\
\text { E do ponto de vista econômico, eu não sei se existe ainda no Brasil }[\ldots] \text { uma } \\
\text { cultura também de a iniciativa privada querer se alinhar à academia em } \\
\text { projetos de inovação, como já acontece no exterior. }\end{array}$ \\
\hline
\end{tabular}




\begin{tabular}{|l|l|}
\hline \multicolumn{2}{|c|}{ Quadro 6. Limites - Política Institucional. (Continuação) } \\
\hline \multirow{3}{*}{ LÍDEO DO YOUTUBE } & $\begin{array}{l}\text { Limites - Política Institucional o Marco Legal por si só, ele não vai adiantar de nada. Vai depender de } \\
\text { postura de cada um de nós. } \\
\text { Então, precisamos realmente de uma mudança de postura das nossas } \\
\text { instituições para fazer a coisa acontecer. }\end{array}$ \\
\hline
\end{tabular}
Fonte: Elaboração dos autores.

Portanto, para que se estabeleça uma cultura de inovação é necessária uma mudança exatamente nos atuais valores, crenças e hábitos existentes nos diferentes atores inseridos no contexto da inovação. Inclusive, conforme Maximiano (2009), algumas das disfunções da cultura organizacional explicam exatamente as afirmações dos entrevistados: dificuldade de enfrentar mudanças ambientais (nesse caso a revitalização de uma lei) e a resistência às necessidades de mudança interna (nesse caso estabelecer a política institucional).

\subsection{Relação entre público e privado}

De forma geral os entrevistados buscam destacar que o Marco Legal da Inovação de 2016 possibilitará maior aproximação entre as ICTs e empresas. O entrevistado 1 destaca que há mais instrumentos jurídicos na Lei 13.243/2016 que irão permitir uma maior variedade de canais de relacionamento entre o público e o privado. O entrevistado 2 reforça a ideia de que vários gargalos anteriormente existentes nas parcerias foram resolvidos com a lei 13.243/2016. Já o entrevistado 4 afirma que a Lei 13.243/2016 aproximará os setores público e privado.

De fato, se analisarmos a Lei de Inovação de 2016, alguns artigos reforçam as ideias dos entrevistados. $\mathrm{O}$ artigo $4^{\circ}$, que aborda o compartilhamento de laboratórios e equipamentos públicos, é um exemplo.

Com essas possibilidades jurídicas haveria maior capacidade para inovar e maior facilidade de relacionamento entre o público e o privado. Já dentre os limites, o entrevistado 1 destaca que, apesar de todos os avanços da Lei 13.243/2016, deve-se preservar o patrimônio público. Um mínimo de controle deverá ser estabelecido para que a relação entre o público e o privado não seja baseada na exploração de um sobre o outro, afinal a ICT pública é mantida pela contribuição de toda uma sociedade e deve ser, portanto, protegida.

Em relação aos limites, o Quadro 7 apresenta uma síntese das opiniões.

Quadro 7. Limites - Relação Entre Público e Privado.

\begin{tabular}{|c|l|}
\hline \multicolumn{2}{|c|}{ Limites - Relação Entre Público e Privado } \\
\hline ENTREVISTADO 3 & $\begin{array}{l}\text { Essa é uma das maiores barreiras que ficaram ainda presentes, que é } \\
\text { uma questão cultural, atávica, do político e do gestor público brasileiro, } \\
\text { que é criar essa dicotomia entre público e privado, que é induzida pela } \\
\text { ação do Estado. }\end{array}$ \\
\hline ENTREVISTADO 4 & $\begin{array}{l}\text { Eu vejo no Brasil uma distância muito presente entre o que é a indústria, } \\
\text { a iniciativa privada, o mundo dos negócios, o mundo business, da } \\
\text { academia. }\end{array}$ \\
$\begin{array}{l}\text { Limites do ponto de vista cultural. Eu não diria nem que são de cunho } \\
\text { meramente ideológico. O que poderia sim ser um limite é a própria cultura } \\
\text { na academia brasileira de que o mais importante é publicar do que criar } \\
\text { empresa. }\end{array}$ \\
\hline
\end{tabular}

Fonte: Elaboração dos autores. 
A crítica ao modelo linear feita por Kline e Rosenberg (1986) se enquadra nas falas dos especialistas: o modelo se baseia exatamente no fato de não haver interação entre os diferentes atores envolvidos na inovação. Para que a inovação ocorra de fato é necessária essa interação, pouco percebida no modelo linear.

\subsection{Empreendedorismo}

A primeira possibilidade é a mudança no regime de trabalho dos professores com dedicação exclusiva, alterada pela Lei de Inovação de 2016. Isso está previsto no Artigo 21 da referida Lei, que admite, sob regulamentação da IFE, retribuição pecuniária em projetos institucionais de ensino, pesquisa e extensão, em atividades esporádicas de colaboração que não ultrapassem 8 horas semanais ou 416 horas anuais.

Costa et al. (2011) afirma que dentre as muitas ações possíveis que desencadeiam o empreendedorismo no ambiente das universidades está a relação entre docentes e discentes com o setor produtivo, em atividades que envolvem a prestação de serviços, e a criação de empresas juniores e a criação de empresas incubadas.

Alguns entrevistados acreditam que a 13.243/2016 permitirá a geração de startups e de empreendedorismo como um todo. As universidades possuem grande potencial de conhecimento que poderá ser utilizado para criação de novas empresas visto que os instrumentos jurídicos do Marco Legal de Inovação de 2016 irão possibilitar melhor uso para as incubadoras de empresas e os parques tecnológicos.

Quanto aos limites, o destaque novamente vai para a questão cultural. Há tanto a falta de tradição das empresas investirem em P\&D como das próprias ICTs e pesquisadores em quererem empreender e sair da tradição da lógica linear da inovação. Se não houver mudanças de ambos os lados nunca haverá uma comunicação e um relacionamento com vistas a gerar empreendedorismo.

Filho et al. (2014) ressaltam que há no Brasil um alto custo para se iniciar e desenvolver novas empresas, principalmente do ponto de vista tributário, indo ao encontro às afirmações do entrevistado 4 quanto à existência de um ambiente de negócios hostil. $\mathrm{O}$ Estado brasileiro deve rever pontos como o excesso de burocracia e tributação, que atrasam e desmotivam ações empreendedoras, de modo a tornar a política pública de inovação mais intersetorial e, consequentemente, mais efetiva.

\subsection{Papel dos órgãos de controle}

Um entrevistado acredita que a pressão pela mudança fará com que os órgãos de controle não entravem os avanços jurídicos estabelecidos pela Lei 13.243/2016. Além disso, ao comparar a lei de 2004 com a de 2016, afirma que aquela possuía ambiguidade, o que dava mais margem para os órgãos de controle atuarem. Isso provavelmente se reverterá no cenário atual. Outro entrevistado afirma que com o novo panorama legal será menos burocrática a relação das atividades das ICTs com os órgãos de controle, devido à maior clareza jurídica. Entretanto, o entrevistado 3 acredita que a criação do Marco Legal de Inovação de 2016 poderá forçar uma mudança cultural dos próprios órgãos de controle no que tange às interpretações oriundas do contexto da inovação.

Quanto aos limites, o entrevistado 3 e um especialista (vídeo do youtube) deixam claro que não acreditam em uma real mudança na orientação restritiva que esses órgãos já exercem. 
Quadro 8. Limites - Papel dos Órgãos de Controle.

\begin{tabular}{|c|c|}
\hline \multicolumn{2}{|r|}{ Limites - Papel dos Órgãos de Controle } \\
\hline ENTREVISTADO 3 & $\begin{array}{l}{[\ldots] \text { eu tenho certeza que continuaremos tendo enormes barreiras, }} \\
\text { porque a maior parte dessas barreiras são culturais, elas são em relação } \\
\text { ao entendimento do que significa inovação e do que significa risco, } \\
\text { quando se fala de inovação. } \\
{[\ldots] \text { quem não tem segurança no que faz são os agentes de controle. Não }} \\
\text { adianta mudar a lei, teria que mudar os agentes de controle". } \\
\text { [...] a minha atuação e a minha experiência (...) me levam a crer que } \\
\text { continuaremos com os mesmos problemas, porque eles provavelmente } \\
\text { vão buscar novas formas de 'complexificar' o processo de transformação } \\
\text { do conhecimento em riqueza. }\end{array}$ \\
\hline VÍDEO DO YOUTUBE & $\begin{array}{l}\text { "Em Brasília a gente tem os coleguinhas do bem e os coleguinhas do mal. O } \\
\text { MCDIC, o MCTI é quem "tá' tentando fazer as coisas acontecerem, ajudando } \\
\text { a construir o Marco Legal mais próximo da realidade que a gente precisa. Por } \\
\text { outro lado, a gente tem a Fazenda, os órgãos de controle, aquele monte de } \\
\text { "U" que tá olhando para aquilo e tentando puxar o trem." }\end{array}$ \\
\hline
\end{tabular}

Fonte: Elaboração dos autores.

De forma a corroborar com as afirmações dos entrevistados há a alegação de que existe:

[...] uma tendência conhecida da prática da administração pública brasileira, refratária à aproximação com o setor privado, bem como receosa da reprovação, por parte de órgãos de controle, quanto a eventuais ações fomentadoras que impliquem aportes de benefícios patrimonialmente valoráveis do Estado à iniciativa privada (Bucci, 2017, p. 295).

De um lado há a Lei 13.243/2016, com suas novas possibilidades jurídicas, e do outro os órgãos de controle que podem vir a entravar toda a dinamicidade. Não se discute a necessidade desses órgãos de realizar suas atribuições. Contudo, é necessária uma mudança no sentido de não prejudicarem aspectos que não seriam de fato problemáticos para o alcance da inovação. Por mais claro que o Marco Legal de Inovação de 2016 seja, mesmo com seu decreto de regulamentação, uma mudança cultural também é necessária no âmbito dos órgãos de controle.

\subsection{Fontes de financiamento}

Analisando as falas dos entrevistados é praticamente unânime a opinião de que a fonte de financiamento pública sustenta os sistemas de inovação. Contudo, o financiamento privado é bem-vindo. Nesse sentido, há mais mecanismos legais que possibilitarão a entrada dessa fonte de recurso com o Marco Legal de Inovação de 2016. Nesse caso, quanto mais opções de fontes de financiamento, melhor. Sendo o investimento do Estado essencial à inovação a sua falta acarreta um enorme descompasso com os avanços da nova política de inovação, o investimento privado não o supre. 
Se por um lado os entrevistados afirmaram que o financiamento público é imprescindível, por outro lado eles abordam um grande limite que é a diminuição desse tipo de investimento nos últimos anos.

Um tópico de grande relevância que ficou fora das preocupações do legislador brasileiro, e é defendido com ênfase pelo entrevistado 4, é a questão das doações de pessoas jurídicas e físicas, em especial ex-alunos, às ICTs, o endowment, que não está contemplado no novo Marco Legal e que seria uma possível fonte de financiamento à inovação. Em um cenário econômico de cortes e contingenciamento de gastos que afeta diretamente as Instituições de Ensino Superior brasileiras, a prática e a cultura do endowment surge como uma alternativa desejável no tocante à sustentabilidade financeira destas instituições.

\subsection{Discussão dos resultados}

Conforme os resultados apresentados é possível apresentar um quadro sintético com os limites e possibilidades da Lei 13.243.

Quadro 9. Síntese dos resultados.

\begin{tabular}{|c|c|c|}
\hline CATEGORIAS & POSSIBILIDADES & LIMITES \\
\hline Política Institucional & $\begin{array}{l}\text { - } \text { Autonomia na elaboração da } \\
\text { Política de Inovação Institucional; } \\
\text { - Respeito à individualidade } \\
\text { institucional; } \\
\text { - Poderá fomentar a cultura da } \\
\text { inovacão. }\end{array}$ & $\begin{array}{l}\text { - Falta de uma cultura de inovação; } \\
\text { - Lei recente, poderá sofrer } \\
\text { modificações na medida que for } \\
\text { implementada. }\end{array}$ \\
\hline Relação Público Privado & $\begin{array}{l}\text { - Diversidade de instrumentos } \\
\text { jurídicos para o relacionamento } \\
\text { entre o público e o privado; } \\
\text { - Aproximação entre público e } \\
\text { privado. }\end{array}$ & $\begin{array}{l}\text { - Cultura acadêmica voltada para } \\
\text { publicações; } \\
\text { - Brasil ainda na lógica do modelo } \\
\text { linear. }\end{array}$ \\
\hline Empreendedorismo & $\begin{array}{l}\text { - Professores poderão dedicar-se } 08 \\
\text { horas semanais em projetos de } \\
\text { inovação; } \\
\text { - Mais meios de efetivar o } \\
\text { empreendedorismo. }\end{array}$ & $\begin{array}{l}\text { - Falta de uma cultura do } \\
\text { empreendedorismo } \\
\text { universidade; } \\
\text { - Falta de uma tradição das } \\
\text { empresas de investirem em P\&D; } \\
\text { - Dificuldades burocráticas para } \\
\text { novas empresas e alta tributação. }\end{array}$ \\
\hline Papel dos Órgãos de Controle & $\begin{array}{l}\text { - Lei e decreto mais claros } \\
\text { possibilitando melhor entendimento } \\
\text { pelos órgãos de controle; } \\
\text { - A pressão dos entes envolvidos } \\
\text { com a inovação bem como a própria } \\
\text { lei poderão gerar uma nova cultura } \\
\text { de interpretação nos órgãos de } \\
\text { controle. }\end{array}$ & $\begin{array}{l}\text { - Falta de uma cultura do } \\
\text { entendimento da inovação; } \\
\text { - Podem continuar a entravar os } \\
\text { avanços da Lei } 13.243 / 2016 \text {. }\end{array}$ \\
\hline Fontes de Financiamento & $\begin{array}{l}\text { - O investimento público é } \\
\text { imprescindível; } \\
\text { - O investimento privado acontecerá } \\
\text { de forma mais natural. }\end{array}$ & $\begin{array}{l}\text { - Diminuição do investimento } \\
\text { público nos últimos anos; } \\
\text { - A lei não abarca o endowment. }\end{array}$ \\
\hline
\end{tabular}

Fonte: Elaboração dos autores.

O Marco Legal de Inovação de 2016 é um avanço para a inovação no Brasil, principalmente se comparado com a Lei de Inovação 2004. A lei está mais clara, regulamentada com maior precisão do legislador, muito embora ainda haja descuidos 
normativos, e consegue abarcar várias questões que eram necessárias para fortalecer o Sistema Nacional de Inovação. Porém, o Marco Legal por si só não é suficiente para fortalecer a inovação no contexto das ICTs. O motivo principal deve ser visualizado na grande barreira cultural que perdura no Brasil, tanto da academia quanto das próprias empresas e órgãos governamentais, a qual representa um enorme desafio. É imprescindível uma mudança de costumes, práticas e atitudes dos gestores públicos, dos pesquisadores, empresários e dos atores políticos quanto à inovação para que o Brasil possa avançar nessa área.

Outro ponto relevante é que o próprio Estado brasileiro se contradiz em seu propósito quanto à inovação, pois, de um lado ele instaura um novo instrumento jurídico, acenando para uma mudança de paradigma no que tange ao ambiente de inovação e à autonomia tecnológica nacional, e do outro lado ele continua com suas disfunções burocráticas referentes ao controle, além de também diminuir os incentivos voltados à inovação prejudicando a si mesmo, na medida em que contribui para a permanência de diversos estigmas quanto ao setor como a ineficiência, o baixo retorno propiciado pelo pagamento de impostos e a improdutividade de seus servidores.

Ao elaborar uma política pública de inovação, é imperioso que o Estado atue de forma intersetorial para que os avanços não sejam reféns de uma limitação governamental existente, seja ela econômica, cultural, procedimental, etc. As muitas possibilidades de avanço que o novo Marco Legal de Inovação abarca sairão do papel para aqueles que de fato focarem seus esforços na superação de seus limites institucionais. Isto posto, o Marco Legal de Inovação de 2016 exigirá, antes de mais nada, que as próprias pessoas inovem.

\section{Conclusões}

Os resultados demonstraram que o novo Marco Legal de Inovação é um avanço desejável para as ICTs, pois proporcionará autonomia, mais instrumentos jurídicos aptos a incentivar a relação e a consequente aproximação entre os setores público e privado, maior possibilidade aos pesquisadores para empreenderem legalmente e mais clareza e, portanto, segurança jurídica para que os gestores públicos possam agir e interpretar a lei. Quanto aos limites, verificou-se que há uma cultura avessa à inovação no Brasil por parte da academia, dos empresários e do próprio governo. Se essa barreira cultural não for devidamente enfrentada e superada pelos agentes e instituições abarcadas pela lei de inovação, ela perde efetividade e até mesmo o seu propósito, pois passa ao largo de práticas e costumes arraigados na cultura do gestor público brasileiro, dos órgãos de controle, representantes da indústria e até mesmo do setor educacional.

A presente pesquisa possui como limitação o fato de que foram ouvidos apenas quatro especialistas da área de inovação. Além disso, como a Lei 13.243/2016 é recente, foi difícil encontrar referências bibliográficas atuais sobre o novo Marco Legal, de modo a ampliar a discussão. Outra limitação foi a falta entrevistas com algum especialista dos seguintes segmentos: sindicato dos docentes de ensino superior, órgãos de controle, empresas e redes de cooperação, ou seja, ouvir alguém que está inserido no contexto diretamente impactado pelo Marco Legal de Inovação de 2016.

Como sugestão para futuras pesquisas, seria interessante analisar as ações que as ICTs ou as empresas estarão realizando para se adequarem ao novo Marco Legal de forma a investigar se está havendo uma mudança cultural e procedimental nessas instituições. Além 
disso, estudos centrados na análise conjuntural da relação universidade-empresa e seus impactos seriam com o desenvolvimento e a efetiva aplicação dos instrumentos disponibilizados pelo novo Marco Legal da Inovação, iniciativas louváveis, projetando um percurso natural das potenciais mudanças provocadas pela nova regulamentação. Neste cenário, é possível realizar um escopo maior de entrevistas na medida em que a lei vai sendo assimilada tanto pelos especialistas quanto outros atores inseridos no Sistema Nacional de Inovação.

\section{Referências}

Albuquerque, E. M. Sistema nacional de inovação no Brasil: uma análise introdutória a partir de dados disponíveis sobre a ciência e a tecnologia. Revista de Economia Política, São Paulo, v. 16, n. 3, p. 56-72, 1996.

Arbix, G. Caminhos Cruzados: Rumo a uma estratégia de desenvolvimento baseada na inovação. Novos Estudos, São Paulo, CEBRAP [online], n. 87, p. 13-33, 2010.

Arbix, G. (2016). 2002-2014: Trajetória da inovação no Brasil. Disponível em: $<$ http://library.fes.de/pdf-files/bueros/brasilien/12962.pdf $>$. Acesso em: 15 de novembro de 2017.

Bardin, L. Análise de Conteúdo. Coimbra: Edições Loyola, 2010. 281p.

BRASIL. Lei $\mathrm{N}^{\mathrm{o}}$ 13.243, de 11 de janeiro de 2016. Disponível em: $<$ http://www.planalto.gov.br/ccivil_03/_ato2015-2018/2016/lei/113243.htm> Acesso em: 26 de novembro de 2017.

BRASIL. Lei $\mathrm{N}^{0} 10.973$, de 2 de dezembro de 2004. Dispõe sobre incentivos à inovação e à pesquisa científica e tecnológica no ambiente produtivo e dá outras providências. Disponível em: < http://www.planalto.gov.br/ccivil_03/_ato2004-2006/2004/lei/110.973.htm> Acesso em: 21 de janeiro de 2018.

BRASIL. Decreto $\mathrm{N}^{\mathrm{o}}$ 9.283, de 07 de fevereiro de 2018. Disponível em: < http://www.planalto.gov.br/ccivil_03/_Ato2015-2018/2018/Decreto/D9283.htm> Acesso em: 25 de março de 2018.

BRASIL. Lei $\mathrm{N}^{\mathrm{o}}$ 12.772, de 28 de dezembro de 2012. Disponível em: < http://www.planalto.gov.br/ccivil_03/_ato2011-2014/2012/lei/112772.htm> Acesso em: 01 de maio de 2018.

Bucci, M. P. D., \& Coutinho, D. R. Arranjos jurídico-institucionais da política de inovação tecnológica: uma análise baseada na abordagem de direito e políticas públicas. In: Diogo R. Coutinho, Maria Carolina Foss, Pedro Salomon B. Mouallem (org.). Inovação no Brasil: avanços e desafios jurídicos e institucionais, São Paulo: Editora Edgard Blücher Ltda, cap. 12, p. 313-341, 2017. 
Cavalcante, L. R. Consenso difuso, dissenso confuso: paradoxos das políticas de inovação no Brasil. Brasília: IPEA - Instituto de pesquisa econômica aplicada, 2013.

Costa, D. M., Barbosa, F. V., \& Da Silva, C. H. P. Empreendedorismo e Inovação: O Papel Da Educação Superior Nas Economias Mundiais. XI Colóquio Internacional Sobre Gestão Universitária na América do Sul, Florianópolis, 7 a 9 de dezembro de 2011.

De Negri, J. A., \& Lemos, M. B. (2009). Avaliação das Políticas de Incentivo à P\&D e Inovação Tecnológica no Brasil. Nota Técnica do IPEA.

Filho, N. M., Komatsu, B., Lucchesi, A., \& Ferrario, M. Políticas de Inovação no Brasil. INSPER, Centro de Políticas Públicas, Policy Paper, n. 11, 2014.

Kline, S. J. \& Rosenberg, N. An overview of innovation, pp. 275-306. In R Landau \& N Rosenberg (eds.). The positive sum strategy. National Academy Press, Washington, 1986.

Machado, D. D. P. N., Gomes, G., Trentin, G. N. S., \& Silva, A. Cultura De Inovação: Elementos Da Cultura Que Facilitam a Criação De Um Ambiente Inovador. RAI - Revista de Administração e Inovação, v. 10, n. 4, p. 164-182, 2014.

Marinho, B. C., \& Corrêa, L. D. P. Novo marco legal da inovação no Brasil: breve análise dos Reflexos das alterações na lei $n^{0}$ 10.973/2004 para os núcleos de Inovação Tecnológica. Revista de Direito, Inovação, Propriedade Intelectual e Concorrência. Brasília, v. 2, n. 1, p. 43-58, 2016.

Matias-Pereira, J. Uma avaliação das políticas públicas de incentivo a inovação tecnológica no Brasil: a Lei do Bem. Parcerias Estratégicas, Edição Especial, Brasília-DF, v. 18, n. 36, p. 221-250, 2013.

Matias-Pereira, J., \& Kruglianskas, I. Gestão de inovação: a lei de inovação tecnológica como ferramenta de apoio às políticas industrial e tecnológica do Brasil. RAE electrônica, v. 4, n. 2, 2005.

Maximiano, A. C. A. Teoria geral da administração: da revolução urbana à revolução digital. 6a edição, São Paulo: Atlas, 491 p., 2009.

Mello, J. M. C., Maculan, A. M., \& Renault, T. Brazilian Universities and their Contribution to Innovation and Development. In: GORANSSON, B.; BRUNDENIUS, C. (Org.). Developing Universities: the changing role of academic institutions in development. Londres: Routledge/IDRC, p. 1-25, 2009.

Morel, R. L. D. M. Ciência e estado: a política científica no Brasil. São Paulo: T. A. Queiroz, p. 23-71, 1979. 
Nazareno C. As mudanças promovidas pela Lei $\mathrm{n}^{\circ}$ 13.243, de 11 de janeiro de 2016 (novo Marco Legal de Ciência, Tecnologia e Inovação) e seu impactos no setor. Brasília: Consultoria Legislativa da Câmara dos Deputados, 2016. Disponível em: $<$ file://C:/Users/marco/Downloads/mudan\%C3\%A7as\%20_promovidas_nazareno.pdf $>$. Acesso em 15 de Janeiro de 2018.

Oliveira, J. O. Ciência, tecnologia e inovação no Brasil: poder, política e burocracia na arena decisória. Revista de Sociologia e Política, v. 24, n. 59, p. 129-147, set. 2016.

Rauen, C. V. O Novo Marco Legal Da Inovação No Brasil: O Que Muda Na Relação Ict-Empresa? Radar, n. 43, p. 21-35, 2016.

SILVA, A. H., \& FOSSÁ, M. I. T. Análise De Conteúdo: Exemplo De Aplicação Da Técnica Para Análise De Dados Qualitativos. Qualitas Revista Eletrônica, v. 16, n. 1, p. 114, 2015.

Suzigan, W., \& Albuquerque, E. M. A interação entre universidades e empresas em perspectiva histórica no Brasil. Belo Horizonte: UFMG/Cedeplar, 2008.

Velho, L. Conceitos de Ciência e a Política Científica, Tecnológica e de Inovação. Sociologias, Universidade Federal do Rio Grande do Sul, Porto Alegre, v. 13, n. 26, p. 128-153, 2011.

Vilha, A. M.; Fuck, M. P., \& Bonacelli, M. B. Aspectos das trajetórias das políticas públicas de ciência, tecnologia e inovação no Brasil. In: MARCHETTI, V. (Ed.). Políticas Públicas em Debate, São Paulo: ABCD Maior - UFABC, p. 251-271, 2013.

Weller, w., \& Zardo, S. P. Entrevista narrativa com especialistas: aportes metodológicos e exemplificação. Revista da FAEEBA-Educação e Contemporaneidade, v. 22, n. 40, 2013. 